\title{
CALAGEM E ADUBAÇÃO FOSFATADA PARA O ARROZ EM SOLOS INUNDADOS: I. TEORES DE FERRO E FÓSFORO NOS SOLOS ${ }^{(1)}$
}

\author{
J . W. V.MELLO(2), A.C.RIBEIRO(3), \\ R .F. NOVAIS ${ }^{(3)} \&$ V.H. ALVAREZV.(3)
}

\begin{abstract}
RESUMO
A dinâmica do $P$ em solos e sedimentos inundados tem grande significado ambiental e parece estar fundamentalmente associada às reações de oxirredução dos compostos de ferro. Com o objetivo de verificar os efeitos da calagem e da adubação fosfatada nos teores de Fee P no solo, amostras de nove solos de várzeas do estado de Minas Gerais foram tratadas com dois níveis de calcário e seis níveis de fósforo. Após um período de incubação aeróbica, foram determinados os teores de $\mathrm{Fe}$ e $\mathrm{P}$ dos solos por extração com acetato de amônio, Mehlich-1 e oxalato de amônio. Os solos foram, então, inundados, determinando-se, periodicamente, os teores de fósforo pelo uso do papel aniônico. Verificou-se que a calagem e a adubação fosfatada tenderam a diminuir os teores de $\mathrm{Fe}$ e aumentar os teores de $\mathrm{P}$ extraível por acetato de amônio e pelo Mehlich-1. Em amostras recentemente inundadas, a calagem tendeu a aumentar o fósforo determinado pelo papel aniônico, ao passo que o contrário ocorreu após maior período de inundação das amostras de solo.
\end{abstract}

Termos de indexação: solos alagados, extratores, papel aniônico.

\footnotetext{
(1) Parte da Tese de Doutorado do primeiro autor, apresentada à U niversidade Federal de Viçosa (UFV). Recebido para publicação em abril de 1998 e aprovado em maio de 1999.

(2) Professor Adjunto do Departamento de Solos, Universidade Federal de Viçosa (UFV). CEP 36571-000 Viçosa (MG).

(3) Professor Titular do Departamento de Solos, UFV. Bolsista do CNPq.
} 


\title{
SUMMARY: LIMING AND PHOSPHATE FERTILIZATION OF WATERLOGGED RICE SOILS: I. SOIL FE AND P LEVELS
}

\begin{abstract}
Phosphorus dynamics in waterlogged soils and sediments is environmentally important and seems cl osely related to redox reactions of i ron compounds. In order to verify the effects of liming and phosphorus fertilization on soil Feand $\mathrm{P}$ contents, ninelowl and soil samples from Minas Gerais, Brazil, were treated with two lime and six phosphorus rates. After an aerobic incubation period, the soil $F$ eand $P$ concentrations were determined by ammoniumacetate, Mehlich-1 and ammonium-oxalateextractants. Thesoi Is werethen waterlogged and the "anionic-paper-method" phosphorus content was periodically determined. It was verified that limeand phosphatetended to decreaseF eand increaseP concentrati ons as determined by ammonium-acetate and Mehlich-1 extractions. In recently waterlogged samples, lime tended to increase the "ani oni c-paper" determi ned P, whereas the opposite occurred after a longer period of waterlogging for somesoil samples.
\end{abstract}

Index terms: fl ooded soils, extractants, ani onic-paper.

\section{NTRODUÇÃO}

Em virtude da complexidade que pode assumir a dinâmica do fósforoem sol os inundados, parece difícil avaliar a disponibilidade desse nutriente, para as plantas de arroz, a partir de análises convencionais em amostras secas de solos. Em revisão sobre o assunto, Chang (1978) relatou que o extrator de Olsen ( $\mathrm{NaHCO}_{3} 0,5 \mathrm{~mol} \mathrm{L-1}$ ) tem sido, na maioria dos casos, o mais eficiente, dada a sua aplicabilidade a vários tipos de solos. Alguns trabal hos também têm demonstrado ser o extrator Mehlich-1 $\left(\mathrm{H}_{2} \mathrm{SO}_{4}\right.$ $0,0125 \mathrm{~mol} \mathrm{~L}^{-1}+\mathrm{HCl} 0,05 \mathrm{~mol} \mathrm{~L}-1$ ) adequado para avaliar a disponibilidade de $\mathrm{P}$ para o arroz irrigado por inundação em solos minerais ácidos (Rojas, 1976; Grandeet al., 1986). Goedert et al. (1971) observaram estreita relação entre o P-Mehlich, a fração do P ligado a Fee a produção do arroz irrigado em solo do Rio Grande do Sul.

A redução prévia das amostras de solo tem sido preconizada como uma maneira de melhorar a capacidade de previsão da disponibilidade de fósforo pelos métodos de análise. Ekpete (1976), por exemplo, obteve aumentos nos coeficientes de correlação entre o fósforo absorvido por plantas de arroz e aquele extraído do solo por vários métodos, quando as amostras eram previamente incubadas sob condições anaeróbicas.

Considerando a elevada correlação entre os óxidos de $\mathrm{Fe}$ amorfos e a adsorção de $\mathrm{P}$ em solos inundados (Khalid et al., 1977), o oxalato, utilizado para remover Fe e Al amorfos do solo, pode ser um extrator com boas perspectivas para estimar o fator quantidade de $P$ nesses solos.

A importância do poder tampão deP, nos estudos de disponibilidade defósforo, tem sido demonstrada em inúmeros trabalhos com sol os bem drenados (Holford, 1976; Freireet al., 1985; Muniz et al., 1987), especialmente quando o fator quantidade (P lábil) é avaliado por meio de extratores sensíveis ao poder tampão. Ocorre, porém, que, ao contrário do que se verifica em solos bem drenados, o poder tampão de $\mathrm{P}$ não é uma característica estável em solos inundados. Conforme se pode inferir do trabal ho de Holford \& Patrick J r. (1979), o poder tampão e ofator quantidade de $P$ no sol o variam em função do tempo de inundação. I sso revela a necessidade de estudos sobre a dinâmica dos fatores relacionados com a disponibilidade de $P$ em solos inundados.

A aval iação das alterações nos fatores quantidade e capacidade, à medida que a redução do solo progride, constitui um dos entraves aos estudos de dinâmica do $\mathrm{P}$ em solos inundados. Supõe-se que a magnitude de tais al terações esteja rel acionada com as quantidades de $\mathrm{Fe}^{2+}$ mobilizado pela redução do solo, as quais, por sua vez, parecem depender dos teores de $\mathrm{Fe}$ avaliados pelo Mehlich-1 e acetato de amônio $1 \mathrm{~mol} \mathrm{~L}^{-1} \mathrm{pH} \mathrm{4,8} \mathrm{(Fe} \mathrm{ativo),} \mathrm{conforme}$ demonstrado por Mello et al. (1992). Assim sendo, esses extratores também podem ser importantes no sentido de avaliar a disponibilidade de $\mathrm{P}$ nos solos inundados.

Van der Zee et al. (1987) e Menon et al. (1989) demonstraram que tanto o $\mathrm{P}$ adsorvido reversivelmente ( $\mathrm{P}$ lábil) como a taxa de dessorção do $\mathrm{P}$ no solo podem ser estimados pelo uso de papel filtro impregnado com hidróxido férrico ("papel aniônico"). Presume-se que essa técnica possa ser adaptada para uso em solos inundados, permitindo obter, de maneira simples, dados vali osos para a compreensão dos fenômenos relacionados com a disponibilidade de P para as plantas de arroz irrigado.

Vários trabal hos têm demonstrado que a prática da calagem assume caráter particular em solos inundados (Leiteet al., 1970; Howeler, 1973; Barbosa Filho et al., 1983; Pereira, 1985), daí a necessidade 
de estudos que busquem mel hor compreensão dos múltiplos efeitos da calagem nesses solos, particularmente sobre a disponibilidade de $P$.

Este trabalho foi realizado com os objetivos de: (a) verificar os efeitos da calagem sobre os teores de Fe e P obtidos por extração com acetato de amônio 1 mol L-1 pH 4,8; Mehlich-1 e oxalato de amônio 0,2 mol L-1 pH 3,0, em amostras secas de solo e (b) verificar os efeitos da calagem sobre o $P$ recuperado pelo papel aniônico, em amostras desoloinundadas.

\section{MATE RIAL E MÉTODOS}

Foram utilizadas amostras $(0-20 \mathrm{~cm})$ de nove solos de várzeas de Minas Gerais (Quadro 1). Após destorroadas e peneiradas (0-2,0 mm), as amostras foram secas ao ar, subdivididas em porções de 2,0 dm $\mathrm{dm}^{3}$ e acondicionadas em sacos de polietileno, constituindo as unidades experimentais.

Os tratamentos constaram de combinações de duas doses de calcário ( $\mathrm{C} 0$ e $\mathrm{C} 1$ ) com seis doses de fósforo (P0, P1, P2, P3, P4, P5). As doses de cal cário foram: $\mathrm{CO}=$ sem corretivo e $\mathrm{Cl}=\mathrm{CaCO}_{3}+\mathrm{MgCO}_{3}$ em quantidades suficientes para obter saturações de $54 \%$ de $\mathrm{Ca}$ e $18 \%$ de $\mathrm{Mg}$, considerando a CTC do solo a pH 7,0. No solo 7, entretanto, as saturações foram de 44\%, para Ca, e de $28 \%$, para Mg, em razão de seu alto teor original de $\mathrm{Mg}$. As doses de $\mathrm{P}$ foram diferentes para cada solo, com vistas em obter o máximo rendimento de matéria seca das plantas de arroz dentro do interval o experimental. Para tanto, foram considerados os resultados obtidos em experimentos prévios com esses mesmos solos (Moura Filho, 1990). As doses de P utilizadas foram: $0,60,120,180,240$ e $300 \mathrm{mg} \mathrm{dm}^{-3}$, para os solos 1 e
7; 0, 90, 180, 270, 360 e $450 \mathrm{mg} \mathrm{dm}^{-3}$, para os sol os 4, 5, 6 e 8; e 0, 120, 240, 360, 480 e $600 \mathrm{mg} \mathrm{dm}^{-3}$, para os solos 2, 3 e 9. Diferentes sais $\left(\mathrm{NH}_{4} \mathrm{H}_{2} \mathrm{PO}_{4}\right.$, $\mathrm{CaH}_{2} \mathrm{PO}_{4} \cdot 2 \mathrm{H}_{2} \mathrm{O}$ e $\mathrm{NaH}_{2} \mathrm{PO}_{4}$ ) foram usados como fonte de fósforo, visando ao balanço de nutrientes.

As amostras de solo com a mistura corretiva foram incubadas por 18 dias, quando, então, receberam as doses de $P$, sendo incubadas por mais 30 dias, com umidade próxima a $80 \%$ da capaci dade de campo. Foram, também, aplicadas soluções de uréia e $\mathrm{CaCl}_{2} .2 \mathrm{H}_{2} \mathrm{O}$ para balancear o $\mathrm{N}$ e o $\mathrm{Ca}$ fornecidos pelos fosfatos. Adicionaram-se, ainda, $\mathrm{CaCl}_{2} \cdot 2 \mathrm{H}_{2} \mathrm{O}$ e $\mathrm{MgCl}_{2} \cdot 6 \mathrm{H}_{2} \mathrm{O}$ nos tratamentos sem corretivo a fim de se obter a mesma relação $\mathrm{Ca}: \mathrm{Mg}$ dos tratamentos com corretivo.

Após o período de incubação, foram retiradas subamostras de cada unidade experimental para as análises de $\mathrm{P}$ eFe pelos extratores M ehlich- $1\left(\mathrm{H}_{2} \mathrm{SO}_{4}\right.$ $0,0125 \mathrm{~mol} \mathrm{~L}^{-1}+\mathrm{HCl} 0,05 \mathrm{~mol} \mathrm{~L}-1$ ); acetato de amônio $1 \mathrm{~mol} \mathrm{L-1} \mathrm{pH} \mathrm{4,8} \mathrm{e} \mathrm{oxalato} \mathrm{de} \mathrm{amônio}$ $0,2 \mathrm{~mol} \mathrm{~L}^{-1} \mathrm{pH} 3,0$. As relações solo: solução foram de 5,0 cm3: $50 \mathrm{~mL}$ para Mehlich-1, com $5 \mathrm{~min}$ de agitação; $2,5 \mathrm{~cm}^{3}$ : $15 \mathrm{~mL}$ para acetato, com duas agitações por 5 min e, entre estas, repouso de duas horas; e 1,0 cm3: $10 \mathrm{~mL}$ para oxalato, com agitação por $2 \mathrm{~h}$, no escuro. Em seguida, as amostras de solo foram transferidas para vasos de 3,0 L, onde foi realizado o plantio de arroz, cultivar INCA. Após 15 dias, os vasos foram inundados, mantendo-se uma lâmina de água de 3,0 cm sobre a superfície do sol o. Foram realizadas análises de $P$, diretamente nos vasos, com o uso do "papel aniônico" aos 14 e 28 dias da inundação. Nas análises de P pelo papel aniônico, foi utilizado papel filtro Schleicher \& Schwell 100, impregnado com hidróxido férrico (van der Zee et al., 1987; Menon et al., 1989). A impregnação foi feita por imersão do papel em $\mathrm{FeCl}_{3} 0,4$ mol L-1 e,

Quadro 1. Características químicas e físicas de nove solos de várzea de Minas Gerais

\begin{tabular}{|c|c|c|c|c|c|c|c|c|c|c|c|}
\hline Solo & Areia & Silte & Argila(1) $^{(1)}$ & $\begin{array}{l}\text { Carbono } \\
\text { orgânico }\end{array}$ & $\mathrm{Fe}_{2} \mathrm{O}_{3}{ }^{(3)}$ & $\begin{array}{c}\mathrm{pH} \mathrm{H}_{2} \mathrm{O} \\
1: 2,5\end{array}$ & $K^{(4)}$ & $\left.A\right|^{(5)}$ & $\mathrm{Ca}^{(5)}$ & $\mathbf{M g}^{(5)}$ & $\mathbf{H}+\mathbf{A} \mathbf{I}^{(\mathbf{6})}$ \\
\hline & \multicolumn{6}{|c|}{$\mathrm{g} \mathrm{kg}^{-1}$} & $\mathrm{mg} \mathrm{kg}^{-1}$ & \multicolumn{4}{|c|}{$-\mathrm{mmol}_{\mathrm{c}} \mathrm{dm}^{-3}$} \\
\hline 1 & 870 & 40 & 90 & 15,2 & 5 & 4,5 & 82 & 1,0 & 6,7 & 4,0 & 20,3 \\
\hline 2 & 450 & 110 & 440 & 25,0 & 75 & 5,4 & 54 & 0,0 & 25,7 & 3,3 & 45,7 \\
\hline 3 & 250 & 360 & 390 & 19,8 & 116 & 5,3 & 26 & 0,0 & 0,3 & 1,0 & 19,0 \\
\hline 4 & 230 & 230 & 540 & 27,2 & 113 & 4,8 & 38 & 3,0 & 8,0 & 4,0 & 57,0 \\
\hline 5 & 680 & 90 & 230 & 23,6 & 59 & 5,1 & 167 & 1,0 & 10,0 & 8,0 & 29,3 \\
\hline 6 & 530 & 110 & 360 & 21,8 & 71 & 5,5 & 32 & 0,0 & 17,3 & 8,0 & 31,3 \\
\hline 7 & 690 & 50 & 260 & 25,8 & 46 & 5,6 & 17 & 0,0 & 14,0 & 14,7 & 24,0 \\
\hline 8 & 570 & 120 & 310 & 18,1 & 63 & 5,4 & 22 & 0,0 & 16,7 & 11,7 & 43,0 \\
\hline 9 & 700 & 120 & 180 & 15,5 & 59 & 5,3 & 41 & 0,0 & 12,3 & 6,3 & 32,3 \\
\hline
\end{tabular}

(1) Método da pipeta (EMBRAPA, 1979). ${ }^{(2)}$ Walkley-Black (EMBRAPA, 1979). ${ }^{(3)}$ Ataque sulfúrico (VETTORI, 1969). ${ }^{(4)}$ Extrator




imediatamente após, em $\mathrm{NH}_{4} \mathrm{OH}$ 2,7 mol L-1. Após secagem ao ar, os papéis impregnados foram recortados em tiras de $25 \mathrm{~cm}^{2}$ deárea útil eafixados, com fita adesiva, a suportes plásticos. Esses suportes foram, então, introduzidos nos vasos a $8-10 \mathrm{~cm}$ da superfície dos solos inundados e, após 16 h, as tiras do papel aniônico foram lavadas e colocadas em erlenmeyers com $50 \mathrm{~mL}$ de $\mathrm{H}_{2} \mathrm{SO}_{4}$ 0,4 mol L-1. Após duas horas de contato, com 30 min de agitação, a solução foi filtrada, obtendo-se o extrato.

O fósforo, nos diferentes extratos, foi determinado pelo método do ácido ascórbico (Braga \& Defelipo, 1974) e o Fe por espectrofotometria de absorção atômica. Os extratos com acetato de amônio foram previamente digeridos com água régia $\left(\mathrm{HNO}_{3}\right.$ conc. $+\mathrm{HCl}$ conc. 1:3v/v) para el iminar interferências ao desenvolvimento da cor na análise de $\mathrm{P}$.

Adotou-se o delineamento experimental em blocos ao acaso, com três repetições. As análises de variância foram realizadas separadamente para cada solo, com vistas em atender ao requisito de homogeneidade das variâncias. O efeito do cal cário foi testado pelo teste $F$, e os efeitos das doses de $P$ foram avaliados por meio de regressão, estimandose curvas de resposta a doses de $\mathrm{P}$ dentro de cada dose de calcário. Utilizou-se o teste "t" de Student para avaliar a significância dos coeficientes de regressão até $10 \%$ de probabilidade. Para as correlações, adotou-se o método de Pearson.

\section{RESULTADOS E DISCUSSÃO}

De modo geral, a calagem provocou diminuição $(P<0,01)$ nos teores de $F$ e extraível pelo acetato de amônio (Fe ativo), porém não alterou o Fe extraído por oxalato de amônio (Fe amorfo) e Mehlich-1 (Figura 1), revelando efeito da calagem sobre a estabilidade dos óxidos de F eativos no solo, conforme sugerido por Mello et al. (1992). Para o solo 3, entretanto, no qual os teores de Feamorfo são baixos, percebeu-se efeito da calagem $(P<0,01)$ também sobre o Fe extraível em oxalato de amônio.

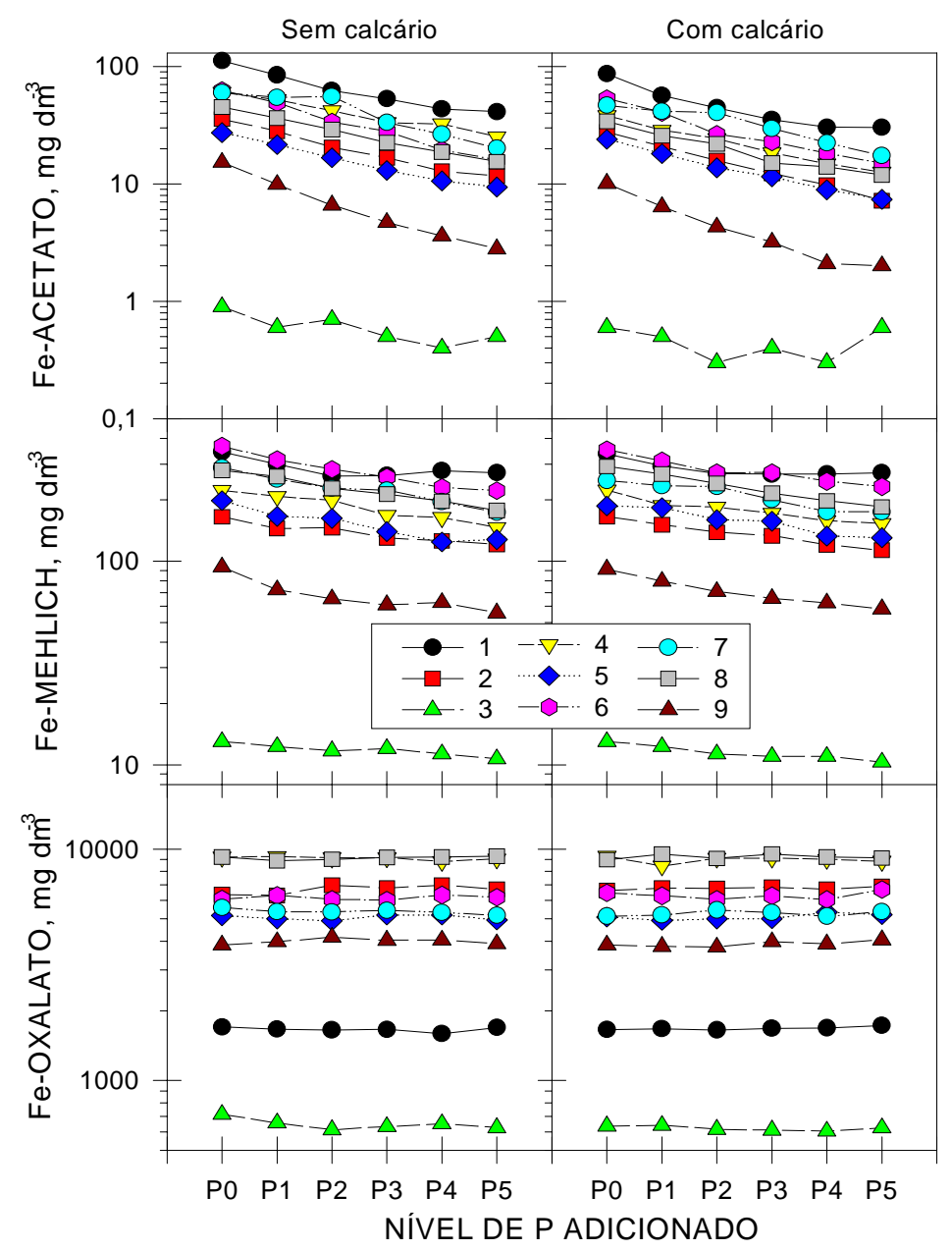

Figura 1. Teores de Feem amostras de nove solos de várzeas, submetidos a seis doses de fósforo na presença e ausência de calcário. 
A adubação fosfatada também provocou decréscimos nos teores de Fe-acetato e Fe-Mehlich. O Fe extraível por oxalato deamônio, demodo geral, não foi alterado pela aplicação de fósforo. Esses resultados indicam que o fosfato aplicado ao solo provavel mente combina-se, preferencialmente, com óxidos de baixa estabilidade, formando compostos mais estáveis. Em revisão sobre o assunto, Goswami \& Banerjee (1978) relataram ser o fósforo aplicado em solos de arroz lentamente convertido a formas ligadas ao ferro ( $\mathrm{P}-\mathrm{Fe}$ ), sendo esse processo influenciado pela presença de óxidos de Fe amorfos. Tem sido demonstrado que os óxidos amorfos, extraíveis em oxalato, são os princi pais responsáveis pela sorção de fósforo em sol os e sedimentos sujeitos a inundações (Shukla et al., 1971; Kuo \& Lotse, 1974; Khalid et al., 1977; Willet, 1979; Kuo \& Mikkelsen, 1979; Sah \& Mikkelsen, 1986). N os experimentos de Sah \& Mikkelsen (1989) e Sah et al. (1989a,b), a fração deF e extraível em oxalato deamônio a pH 6,0 revel ou-se particularmente importante nas reações de sorção de P. Deve-se salientar que o oxalato a pH 6,0 extrai apenas parte dos óxidos extraíveis por oxalato a pH 3,0; presumivelmente uma fração de menor estabilidade.

Em razão dos decréscimos nos teores de $\mathrm{Fe}$ observados com aplicação de calcário e $\mathrm{P}$, pode-se supor que tanto a calagem quanto a adubação fosfatada estabilizam os óxidos de Fe nos solos, podendo limitar a disponibilidade de Fe para as plantas de arroz. Ambas as práticas têm sido recomendadas para minimizar problemas detoxidez deFe para o arroz em sol os submersos (Breemen \& Moormann, 1978). A adubação fosfatada, por exemplo, tem sido considerada como medida de controle da "toxidez indireta" de Fe, decorrente da deposição de óxidos de Fe nas raízes das plantas, o que limita a absorção de nutrientes. Contudo, segundo os resultados obtidos, a aplicação de $\mathrm{P}$ pode diminuir o nível de $\mathrm{Fe}^{2+}$ na solução do solo pela formação de compostos mais estáveis, produto da reação do P com óxidos de F e de baixa estabilidade. I sso está de acordo com o que foi observado por Willet \& Cunningham (1983) eWillet (1985). Segundo esses autores, a adsorção de P na superfície de óxidos de Fe amorfos aumenta-Ihes a estabilidade frente a condições de redução no meio.

Os teores de $\mathrm{P}$ recuperado pelos extratores químicos, em função das doses de $\mathrm{P}$ aplicadas, ajustaram-se, na maioria dos casos, a equações de regressão quadráticas com coeficientes positivos para o componente de segundo grau (Quadro 2). I sso indica que a taxa de recuperação do $P$ adicionado aumentou com o aumento da dose aplicada, principalmente para os extratores Mehlich-1 e acetato de amônio. Tal fenômeno pode ser atribuído a alterações na energia de adsorção das superfícies adsorventes e, ou, aumento da repulsão mútua dos ânions adsorvidos à medida que aumenta a saturação da superfície adsorvente (Kuo \& Lotse, 1974).
Admitindo que o $\mathrm{P}$ aplicado combina-se, preferencialmente, com óxidos de baixa estabilidade (Fe ativo e Fe-Mehlich), pode-se supor que uma proporção maior do P deverá reagir com esses óxidos quando em doses baixas. Com o aumento da dose de $P$, essas matrizes de retenção vão sendo saturadas e quantidades maiores de $\mathrm{P}$ ficariam disponíveis para adsorção em superfícies mais estáveis. A associação de $\mathrm{P}$ com óxidos de $\mathrm{Fe}$ de baixa estabilidade envolveria adsorção específica e, ou, reações de precipitação, de modo que os compostos assim formados seriam mais estáveis à ação dos extratores. Essa hipótese pode ser considerada para explicar tanto a diminuição nos teores de Fe-acetato e FeMehlich, quanto o aumento na taxa de recuperação do P com o aumento das doses aplicadas.

Verifica-se que a calagem provocou aumento nas taxas de recuperação deP pel os extratores Mehlich-1 eacetato de amônio. Talvez, ao estabilizar os óxidos de Fe ativos (extraíveis em acetato de amônio) nos solos, a calagem provoque diminuição na superfície disponível para adsorção específica e, ou, reações de preci pitação, refletindo-se em aumentos na taxa de recuperação do $\mathrm{P}$ adicionado.

O modo de ação do extrator Mehlich-1 é relativamente bem conhecido. Considera-se que esse extrator atua, principal mente, por sol ubilização dos fosfatos de $\mathrm{Ca}$, de Fe e de Al e, por troca aniônica (Thomas \& Peasle, 1973). Por outro lado, existem poucas informações sobre acetato e oxalato de amônio como extratores de P. Acredita-se que esses extratores atuem, principalmente, sobre o $\mathrm{P}$ associado a óxidos de $\mathrm{Fe}$ ativos e amorfos, respectivamente. $\mathrm{O}$ fato de a recuperação do $\mathrm{P}$ pel os extratores acetato e oxalato ter sido, de modo geral, maior para os sol os com teores mais el evados de Fe ativo e amorfo (Figura 1 e Quadro 2) corrobora essa hipótese. Contudo, não se deve esperar que esses extratores atuem, exclusivamente, sobre o P ligado a óxidos de Fe.

Apesar dos altos coeficientes de variação nas análises de $P$ pelo método do "papel aniônico" (dados não mostrados), os resultados obtidos (Figura 2) confirmaram as tendências observadas para os extratores químicos. De modo geral, foram obtidos aumentos no $P$ recuperado pel o papel aniônico com a calagem. Esses aumentos foram mais evidentes para as análises realizadas no dia da inundação. Para tempos de inundação mais prolongados, verificouse que, em muitos casos, ou esses aumentos não foram significativos $(P<0,10)$ ou a calagem provocou diminuição no $\mathrm{P}$ recuperado, como é o caso do solo 1 , aos 14 dias de inundação, e do solo 4, aos 28 dias de inundação. Esses resultados refletem, provavelmente, efeitos do aumento de pH, com o tempo deinundação, sobrea solubilidade dos fosfatos de cál cio, desde que se admita a hipótese de formação desses compostos nos solos com cal cário. 
Quadro 2. Parâmetros das equações de regressão para $\mathbf{P}$ recuperado de amostras dos solos de várzeas pelos extratores químicos $\left(Y, \mathrm{em} \mathrm{mg} \mathrm{dm}^{-3}\right.$ ) em função das doses de $P$ adicionadas $\left(X, \mathrm{em} \mathrm{mg} \mathrm{dm}^{-3}\right)$

\begin{tabular}{|c|c|c|c|c|c|c|}
\hline \multirow{2}{*}{ Solo } & \multicolumn{3}{|c|}{ Sem calcário } & \multicolumn{3}{|c|}{ Com calcário } \\
\hline & bo & b1 $\times 10$ & b11 $\times 10^{4}$ & bo & b1 x 10 & b11 $\times 10^{4}$ \\
\hline \multicolumn{7}{|c|}{ Acetato de amônio, $1 \mathrm{~mol} \mathrm{~L}^{-1}$ pH 4,8 } \\
\hline 1 & 2,26 & 1,360 & & 1,91 & 1,411 & 1,634 \\
\hline 2 & 1,15 & 0,185 & 0,495 & 0,91 & 0,265 & 0,602 \\
\hline 3 & 0,51 & $-0,015$ & 0,646 & 0,64 & $-0,049$ & 0,802 \\
\hline 4 & 1,56 & 0,071 & 0,458 & 1,56 & 0,078 & 0,738 \\
\hline 5 & 0,33 & 0,242 & 0,717 & 0,88 & 0,130 & 1,365 \\
\hline 6 & 1,22 & 0,192 & 1,019 & 1,69 & 0,142 & 1,393 \\
\hline 7 & 0,57 & 0,098 & 1,102 & 0,40 & 0,213 & 0,952 \\
\hline 8 & 1,37 & 0,230 & 0,813 & 0,78 & 0,520 & $0,422^{0}$ \\
\hline 9 & 0,53 & 0,245 & 0,970 & 0,52 & 0,396 & 1,209 \\
\hline \multicolumn{7}{|c|}{ Melhich-1 } \\
\hline 1 & 4,54 & 2,695 & 4,400 & 4,90 & 2,596 & 7,037 \\
\hline 2 & 5,49 & 0,576 & 0,965 & 5,20 & 0,719 & 1,076 \\
\hline 3 & 2,07 & 0,607 & 1,035 & 2,99 & 0,587 & 1,274 \\
\hline 4 & 1,19 & 0,896 & & 3,28 & 0,812 & 0,550 \\
\hline 5 & 3,78 & 0,668 & 1,549 & 3,28 & 0,986 & 0,899 \\
\hline 6 & 4,73 & 0,649 & 1,605 & 5,59 & 0,725 & 1,858 \\
\hline 7 & 1,80 & 0,564 & 1,824 & 0,96 & 0,935 & $0,728^{\circ}$ \\
\hline 8 & 2,17 & 0,876 & $0,858^{*}$ & 3,27 & 1,046 & $0,723^{\circ}$ \\
\hline 9 & 2,07 & 1,330 & 0,962 & 1,93 & 1,657 & 1,104 \\
\hline \multicolumn{7}{|c|}{ Oxalato de amônio, $0,2 \mathrm{~mol} \mathrm{~L}^{-1} \mathrm{pH} 3,0$} \\
\hline 1 & 14,74 & 8,007 & & 13,11 & 8,266 & \\
\hline & 39,16 & 6,330 & & 47,44 & 4,745 & 2,857 \\
\hline 3 & 4,97 & 1,823 & 2,964 & 4,90 & 2,169 & 2,224 \\
\hline 4 & 44,18 & 6,959 & & 53,37 & 5,020 & $3,610^{\circ}$ \\
\hline 5 & 29,13 & 4,155 & 3,314 & 20,66 & 5,455 & \\
\hline 6 & 37,24 & 4,444 & $4,891 *$ & 44,74 & 4,729 & $4,385^{\circ}$ \\
\hline 7 & 6,16 & 5,261 & & 4,07 & 5,435 & \\
\hline 8 & 32,41 & 7,940 & & 38,43 & 7,536 & \\
\hline 9 & 20,99 & 6,457 & & 26,33 & 5,145 & 2,425 \\
\hline
\end{tabular}

0 ,* Significativos a 10 e 5\%, respectivamente. Todos os demais coeficientes foram significativos a 1\%. b0, b1 e b11 são os coeficientes da regressão $\left(Y=b 0+b 1 X+b 11 X^{2}\right)$. Todos os coeficientes de determinação foram superiores a $99 \%\left(R^{2}>0,99\right)$.

Para os solos 2, 3 e 5, os aumentos nos teores de $\mathrm{P}$ recuperado pelo papel aniônico, provocados pela calagem, foram, ainda, evidentes aos 28 dias de inundação. Analisando os dados de Mello et al. (1992), verifica-se que os val ores de pH, nesses solos, foram inferiores a 6,2 após 28 dias deinundação para os tratamentos com cal cário, o que torna mais difícil a formação de fosfatos de Ca nesses sol os, em relação aos demais.

O presente experimento não foi planejado de modo que o tempo de inundação pudesse constituir um fator em estudo. Em conseqüência, as análises estatísticas não permitem, a rigor, comparações entre os teores de $\mathrm{P}$ recuperado, pelo papel aniônico, nos diferentes tempos de inundação. Entretanto, a despeito dessa limitação, pode-se perceber uma tendência de aumentos nos teores de $\mathrm{P}$ com otempo de inundação (Figura 2). Esses aumentos foram mais freqüentes para as análises aos 14 dias deinundação em relação àquelas realizadas no início do período de inundação, principalmente nas doses mais baixas de $\mathrm{P}$ aplicado (P1, P2 e P3). Aos 28 dias, já foram observados muitos casos de decréscimos no $P$ recuperado em relação aos 14 dias de inundação, principalmente nas doses mais altas de $\mathrm{P}$ aplicado. Os sol os 2, 4 e 7 sem cal cário ilustram casos em que esses decréscimos ocorreram praticamente para todas as doses de $P$. Os equilíbrios quími cos relatados por Lindsay (1979) revelam a possibilidade de precipitação de fosfatos de $\mathrm{Fe}$ a valores de $\mathrm{Eh}$ relativamentealtos, quando as atividades de $_{2} \mathrm{PO}_{4}$ eF $\mathrm{e}^{2+}$ em solução forem suficientemente altas. Essa hipótese pode ser considerada para explicar os decréscimos no $P$ recuperado, com o tempo de inundação, queforam observados para as doses mais altas de P aplicadas aos solos. 


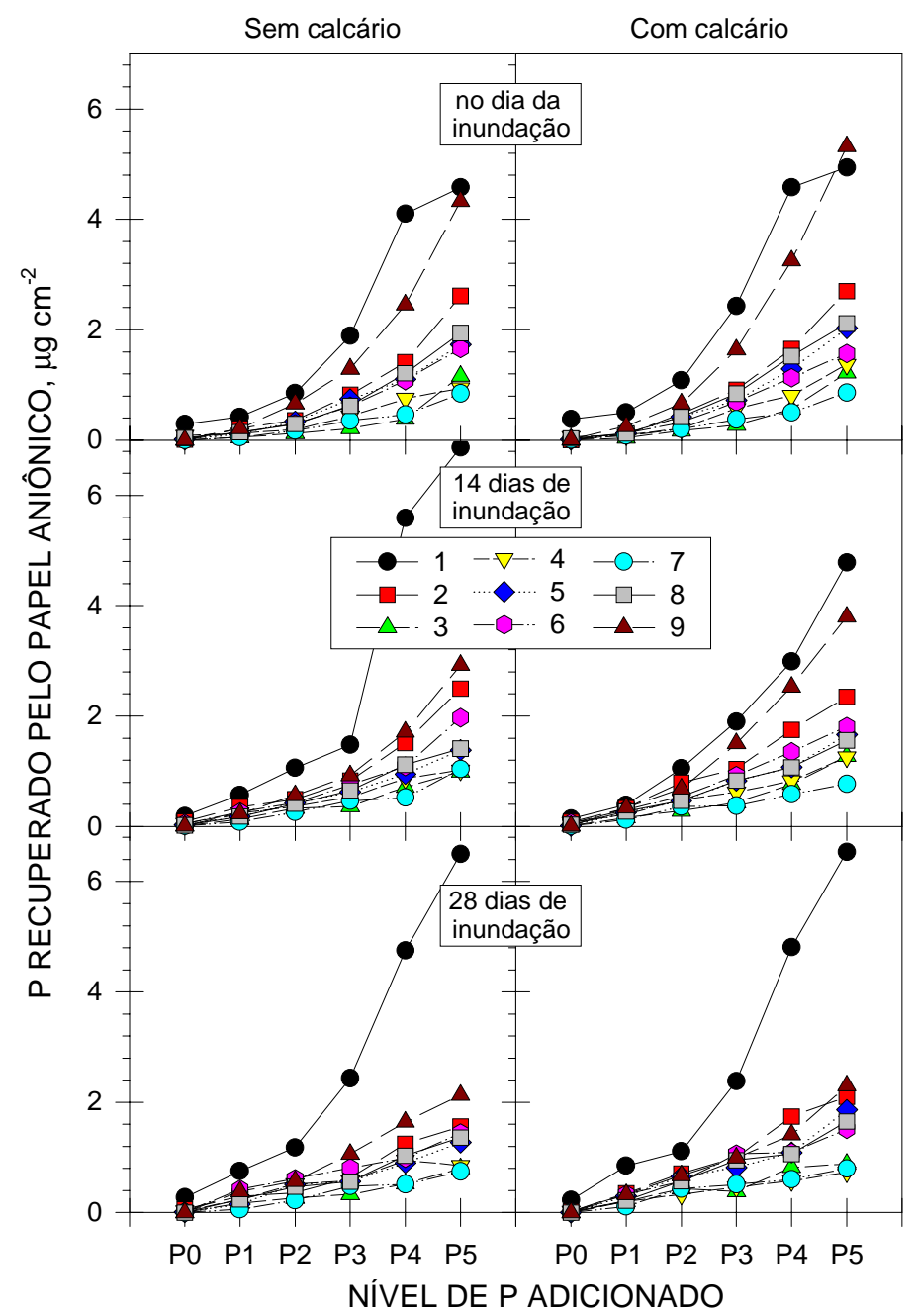

Figura 2. Fósforo recuperado pelo papel aniônico em amostras de nove solos de várzeas, submetidos a seis doses de fósforo na presença e ausência de calcário, considerando diferentes períodos de inundação.

\section{CONCLUSÕES}

1. A calagem e a adubação fosfatada proporcionaram menores teores de Fe extraível por acetato de amônio e pelo Mehlich-1, ao mesmo tempo que promoveram aumentos nos teores de $\mathrm{P}$ recuperado por esses extratores.

2. E $m$ amostras recentemente inundadas, a calagem tendeu a aumentar oP recuperado pel o papel aniônico; ao passo que, após um tempo maior de inundação, a taxa de recuperação do $\mathrm{P}$ chegou a ser diminuída por efeito de calagem, para alguns solos.

\section{LITERATURA CITADA}

BARBOSA FILHO, M.P.; FAGERIA, N.K. \& STONE, L.F. Manejo d'água e calagem em relação à produtividade e toxicidade de ferro em arroz. Pesq. Agropec. Bras., 18:903-910, 1983.
BRAGA, J .M. \& DEFELIPO, B.V. Determinação espectrofotométrica de fósforo em extratos de solo e material vegetal. R. Ceres, 21:73-85, 1974.

BREEMEN, N. van \& MOORMANN, D.S. Iron-toxic soils. In: INTERNATIONAL RICE RESEARCH INSTITUTE. LOS Baños, 1978. p.781-800.

CHANG, S.C. Evaluation of the fertility of rice soils. In: INTERNATIONAL RICE RESEARCH INSTITUTE. LOS Baños, 1978. p.521-541.

DELAZARI, P.C. Disponibilidade de fósforo em solos do estado do Espírito Santo. Viçosa, Universidade Federal de Viçosa, 1979. 42p. (Tese de Mestrado)

EKPETE, D.M. Evaluation of chemical methods for the determination of available phosphorus in waterlogged soils. Soil Sci., 121:217-221, 1976.

EMPRESA BRASILEIRA DE PESQUISA AGROPECUÁRIA EMBRAPA. Serviço Nacional de Levantamento e Conservação de Solos. Manual de métodos de análises de solo. Rio deJ aneiro, 1979. não paginado. 
FREIRE, F.M.; NOVAIS, R.F. \& NEVES, J .C.L. Níveis críticos de fósforo para o crescimento do estilosantes como função do fator capacidade de fósforo do solo. R. Ceres, 32:488-499, 1985.

GOEDERT, W.J .; PATELLA, J .F. \& MORAES, J .F.V. Formas de fósforo num Planossolo do Rio Grande do Sul e sua disponibilidade para a cultura do arroz irrigado. Pesq. Agropec. Bras., 6:39-43, 1971.

GOSWAMI, N.N. \& BANERJ EE, N.K. Phosphorus, potassium and other macroelements. In: INTERNATIONAL RICE RESEARCH INSTITUTE. Los Baños, 1978. p.561-580.

GRANDE, M.A.; CURI, N.\& QUAGGIO,J .A. Disponibilidade de fósforo pelos extratores de Mehlich e resina em solos cultivados com arroz irrigado. R. Bras. Ci. Solo, 10:45-50, 1986.

HOLFORD, I.C.R. Effects of phosphate buffer capacity of soil on the phosphate requirements of plants. Plant Soil, 45:433$444,1976$.

HOLFORD, I.C.R. \& PATRICK J r., W.H. Effects of reduction and $\mathrm{pH}$ changes on phosphate sorption and mobility in an acid soil. Soil. Sci. Soc. Am. J ., 43:292-297, 1979.

HOWELER, R.H. I ron-induced oranging disease of rice in relation to physico-chemical changes in flooded oxisol. Soil Sci. Soc. Am. Proc., 376:898-903, 1973.

KHALID, R.A.; PATRICK J r., W.H. \& DE LAUNE, R.D. Phosphorus sorption characteristics of flooded soils. Soil Sci. Soc. Am. J ., 41:305-310, 1977.

KUO, S. \& LOTSE, E.G. Kinectics of phosphate adsorption and desorption by lake sediments. Soil Sci. Soc. Am. Proc., 38:5054, 1974.

KUO, S. \& MIKKELSEN, D.S. Distribution of iron and phosphorus in flooded and unflooded soil profiles and their relation to phosphorus adsorption. Soil Sci., 127:18-25, 1979.

LEITE, N.; GARGANTINI, H.; HUNGRIA, L.S. \& IGUE, T. Efeitos de nitrogênio, fósforo cal cário e micronutrientes em cultura de arroz irrigado no Vale do Paraíba. Bragantia, 29:273285, 1970.

LINDSAY, W.L. Chemical equilibria in soils. New York, J ohn Wiley, 1979. 449p.

MELLO, J .W.V.; FONTES, M.P.F.; RIBEIRO, A.C. \& ALVAREZ V., V.H. I nundação e calagem em solos de várzea: I. Alterações no pH, no Eh e nos teores de $\mathrm{Fe}^{2+}$ e $\mathrm{Mn}^{2+}$ em solução. R. Bras. Ci. Solo, 16:309-317, 1992.

MENON, R.G.; HAMMOND, L.L. \& SISSINGH, H.A. Determination of plant-available phosphorus by the iron hidroxide-impregnated filter paper $(\mathrm{Pi})$ soil test. Soil Sci. Soc. Am. J ., 53:110-115, 1989.

MOURA FILHO, G. Disponibilidade de fósforo em amostras de solos de várzea. Viçosa, Universidade Federal de Viçosa, 1990. 76p. (Tese de Mestrado)
MUNIZ, A.S.; NOVAIS, R.F.; FREIRE, F.M.; NEVES, J.C.L. \& BARROS, N.F. Disponibilidade de fósforo e recomendação de adubação avaliada por meio de extratores químicos e do crescimento de soja em amostras de solo com diferentes valores do fator capacidade. R. Ceres, 34:125-151, 1987.

PEREIRA, L.F. E feito da aplicação de cal cário, fósforo e zinco no crescimento e nutrição do trigo (Triticum aestivum L.) e arroz (Oryza sativa L.) em dois solos de várzea do estado de Minas Gerais. Lavras, Escola Superior de Agronomia de Lavras, 1985. 135p. (Tese de Mestrado)

ROJ AS, W.C. Selección de metodos para la evaluación de fósforo disponible en suel os arroceros. Agric. Tecn., 36:5-13, 1976.

SAH, R.N. \& MIKKELSEN, D.S. Effects of anaerobic decomposition of organic matter on sorption and transformations of phosphate in drained soils: 2. Effects on amorphous iron content and phosphate transformation. Soil Sci., 142:346-351, 1986.

SAH, R.N. \& MIKKELSEN, D.S. Phosphorus behavior in flooded drained soils. I. Effects on phosphorus sorption. Soil Sci. Soc. Am. J ., 53:1718-1722, 1989.

SAH, R.N.; MIKKELSEN, D.S. \& HAFEZ, A.A. Phosphorus behavior in flooded-drained soils. II. I ron transformation and phosphorus sorption. Soil. Sci. Soc. Am. J ., 53:17231728, 1989a.

SAH, R.N.; MIKKELSEN, D.S. \& HAFEZ, A.A. Phosphorus behavior in flooded-drained soils. III. Phosphorus desorption and availability. Soil Sci. Soc. Am. J ., 53:1729-1732, 1989b.

SHUKLA, S.S.; SYERS, J .K.; WILLIAMS, J .D.H.; ARMSTRONG, D.E. \& HARRIS, R.E. Sorption of inorganic phosphate by lake sediments. Soil Sci. Soc. Am. Proc., 35:244-249, 1971.

THOMAS, G.W. \& PEASLE, D.E. Testing soil for phosphorus. In: WALSH, L.M. \& BEATON, J .D., eds. Soil testing and plant analysis. Madison, Soil Science Society of America, 1973. p.115-132.

van der ZEE, S.E.A.T.M.; FOKKINK, L.G.J . \& van RIEMSDIJ K, W.H. A new technique for assessment of reversibly adsorbed phosphate. Soil Sci. Soc. Am. J ., 51:599-604, 1987.

VETTORI, L. Métodos de análise de solo. Rio de J aneiro, EPE, 1969. 24p. (Boletim Técnico, 7)

WILLET, I.R. The effects of flooding for rice culture on soil chemical properties and subsequent maize growth. Plant Soil, 52:373-383, 1979.

WILLET, I.R. The reductive dissolution of phosphated ferrihydrite and strengite. Aust. J . Soil Res., 23: 237-244, 1985.

WILLET, I.R. \& CUNNINGHAM, R.B. Influence of sorbed phosphate on the stability of ferric hydrous oxide under controlled pH and Eh conditions. Aust. J. Soil Res., 21:301308, 1983. 